\title{
Cardiac Progenitor Cells as Target of Cell and Growth Factor-Based Therapies for Myocardial Regeneration
}

\section{Chiara Sassoli', Sandra Zecchi-Orlandini', Daniele Bani ${ }^{2}$ and Lucia Formigli'*}

${ }^{1}$ Department of Experimental and Clinical Medicine, Section of Anatomy, University of Florence, Largo Brambilla, 3- Viale Pieraccini, 6 - 50134 Florence, Italy ${ }^{2}$ Department of Experimental and Clinical Medicine, Section of Histology, University of Florence, Largo Brambilla, 3- Viale Pieraccini, 6 - 50134 Florence, Italy

\begin{abstract}
It has been recently established that the adult heart harbors a reservoir of myocardial stem/progenitor cells. The regenerative potential of the heart is, however, insufficient to fully restore the functional myocardium after damage, motivating the use of cell- and growth factor-based replacement strategies. In this review, we summarize the progress that has been made in this field and discuss its actual contribution to the stimulation of endogenous mechanisms of myocardial repair/regeneration. Particular emphasis has been paid to paracrine secretion occurring in host tissues as the major mechanism involved in the beneficial outcomes of cell transplantation into the injured myocardium. The advantages of using cell therapy over single and combined growth factor administration have been also extensively discussed.
\end{abstract}

Keywords: Cardiac stem cells; Cardiac regeneration; Cardiotropic hormones; Cell-based therapy; Growth factors

\section{Introduction}

Ischemic heart disease represents the dark aspect of the medal of the improvement of life quality in developed countries, where it can be regarded as a major health issue. Massive death of ventricular cardiomyocytes following acute myocardial infarction (AMI), progressive cardiomyocyte loss due to coronary ischemia and increasing overload on the residual viable myocardium can eventually result in myocardial dysfunction and heart failure [1,2]. The current pharmacological therapies, which are directed to lower blood pressure and cardiac afterload, sustain heart contractility and improve the metabolic derangements predisposing to atherosclerosis, undoubtedly have a major role in the primary and secondary prevention of ischemic heart disease. However, once the vicious cycle to heart failure has started, their overall efficacy is limited and the prognosis is poor. At present, the only available treatment for end-stage heart failure is heart transplantation, which is obviously limited by donor organ shortage and rejection issues [3]. This is mostly due to the lack of effective regenerative capacity in the adult mammalian heart. Indeed, myocardial regeneration varies greatly in phylogenetically different vertebrates, being inversely related to their complexity. In particular, the heart of zebrafish can easily regenerate after non lethal injury [4,5], as can the newt heart [6,7]. On the contrary, the heart of mammals reacts to injury by scarring while regeneration plays a negligible role $[7,8]$. A major reason for such different behaviors consists in the fact that cardiac muscle cells in lower vertebrates retain the ability to de-differentiate, proliferate and re-differentiate under appropriate stimuli [6], whereas this reprogramming capacity is no more exploited by mammal adult cardiomyocytes, so that myocardial regeneration - if any exists - only depends on the very limited pool of cardiac stem/progenitor cells (CSCs) which are distributed throughout the myocardium and at the points of coronary artery branching, in specific cardiogenic niches [917]. This has dramatically changed the traditional view of the heart as a terminally differentiated post- mitotic organ, suggesting that it is in continuous turnover and has intrinsic regenerative potentials [1823]. Although such idea is valid in principle and has been partially confirmed in experimental models, clinical evidence indicates that a functionally relevant myocardial regeneration by CSCs, especially after massive tissue loss, cannot be achieved [22,24,25].
Recent attention has also been pointed at the cardiac stroma, which can behave differently in lower vertebrates and mammals, favoring myocardial regeneration or scarring, respectively. During organ development, form is imprinted in the stromal compartment, which can be considered not only as a mere support for parenchymal cells, but also as a key regulator of cell proliferation, survival, differentiation, and morphogenetic movements [26]. Of note, peculiar stromal cells (telocytes) have been identified in the cardiogenic niches of adult human hearts and in the myocardium of peri-natal developing mouse hearts $[27,28]$. These cells are characterized by numerous, slender cytoplasmic processes (filopodes) forming a sort of scaffold which appears to direct the migration of myocardial precursors during heart morphogenesis. Conversely, in the adult myocardium, stromal cells have conceivably lost their former 'scaffolding' capacity, while they are prompted to differentiate into 'scarring' myofibroblasts by pro-inflammatory growth factors and cytokines. On the above grounds, it is clear that an enhanced understanding of the molecular signals and mechanisms that control heart regeneration in appropriate animal models may help to devise suitable methods to promote therapeutic heart regeneration in humans. In particular, it will be important to define how and at which extent the interaction between myocardial precursor cells and cardiac stromal cells plays a role in heart morphogenesis and regeneration and how this interaction can be modulated to operate a shift from the fibrogenic to the regenerative pattern in the healing heart.

Given that the intrinsic regenerative potential of the adult heart is low and clinically negligible; two lines of thought have directed the research in cardiac regenerative medicine. The first and most obvious line consists in the local transplantation of stem cells. Different cell types

*Corresponding author: Prof. Lucia Formigli, Department of Experimental and Clinical Medicine-Section of Anatomy and Histology, University of Florence, Largo Brambilla, 6-50134 Florence, Italy, Tel: +390554271809; Fax: +390554379500; E-mail: formigli@unifi.it

Received April 30, 2013; Accepted June 10, 2013; Published June 12, 2013

Citation: Sassoli C, Orlandini SZ, Bani D, Formigli L (2013) Cardiac Progenitor Cells as Target of Cell and Growth Factor-Based Therapies for Myocardial Regeneration. J Stem Cell Res Ther S9:004. doi:10.4172/2157-7633.S9-004

Copyright: $\odot 2013$ Sassoli C, et al. This is an open-access article distributed under the terms of the Creative Commons Attribution License, which permits unrestricted use, distribution, and reproduction in any medium, provided the original author and source are credited. 
- mainly bone marrow-derived stromal cells (MSCs) and CSCs have been grafted by different techniques with the aim to repair the damaged heart. More recently, induced pluripotent stem cells (iPSCs) generated from somatic cells via epigenetic and transcriptional reprogramming have been used for cardiac regenerative purpose [29,30]. These cells largely resemble human embryonic stem cells in terms of their pluripotency, surface markers, morphology, proliferation and in vivo teratoma formation. Importantly, iPSCs can be differentiated into cardiomyocytes, although their functionality and the underlying mechanisms require further investigations and scrutiny [29-31].

Cell based therapeutic approach have brought objective improvements of myocardial contractile performance, scarring and adverse heart remodeling together with the stimulation of the endogenous repair mechanisms [14,29-35]. The second line is based on a different approach, which aims at potentiating the intrinsically poor proliferative/differentiative potential of resident CSCs by the administration of suitable growth factors and cardiotropic hormones. This review aims at summarizing and discussing key clues and evidences on these exciting issues.

\section{Cardiac Stem Cells and Progenitors in the Adult Mammalian Heart}

As observed above, adult mammalian myocardium, including that in humans, contains a small pool of cells with the phenotype and behavior of CSCs $[9,10,12,14-17,19,20,22,23]$.

These cells are mainly involved in maintaining cardiac tissue homeostasis throughout life, but they can also contribute to restore the cardiomyocytes and in some cases, the microvessels, lost due various pathological insults $[16,35]$. These cells possess one or more criteria of stem cells (self- renewal, pluripotency, clonogenicity) and have different origin: intra-cardiac origin (stem cells residing within the myocardium and epicardial derived stem cells), and extra-cardiac circulatory sources, such as the bone marrow.

The identification of these cells has been carried out by a number of independent groups on the basis of the expression of specific markers (membrane epitopes and transcriptional factors) in different species. However, whether these markers identify distinct cell population or different developmental and/or physiological phases of the same CSC, is controversial and remains to be fully elucidated [12,15, 35-37].

A variety of CSC populations have been identified so far in the post-natal and adult heart and are distributed throughout the heart: c- $\mathrm{Kit}^{+} / \mathrm{Lin}^{-}$cardiac stem cells; Sca- $1^{+}$cardiac progenitors; Isl1 ${ }^{+}$cardiac progenitors and epicardium derived cells (EPDCs) (Figure 1). Of interest, CSCs can also be obtained from tissue culture of cardiac explants on the basis of their ability when grown in suspension to form aggregates called "cardiospheres", because of their similarity to the pseudoembryoid bodies formed by neural cells, neurospheres.

It has been demonstrated that cardiospheres are composed of heterogeneous cell populations consisting of proliferating c-Kit ${ }^{+}, \mathrm{Sca}-$ $1^{+}$, and Flk- $1^{+}$cells in their core and differentiating cells expressing cardiac and endothelial markers on the periphery $[16,35,38,39]$.

\section{c-Kit ${ }^{+} / \operatorname{Lin}^{-} \mathrm{CSCs}$}

These cells have been characterized by the expression of stem cell factor (SFA; also called c-Kit ligand) receptor, c-Kit (CD117) and by the absence of any markers of the hematopoietic lineages (Lin). The c-kit receptor is a transmembrane protein with tyrosine kinase activity belonging to type III receptor tyrosine kinase family. Binding of c-Kit with SFA through autocrine or paracrine actions, leads to oligomerization and auto-phosphorylation of the receptor and activation of multiple downstream signaling pathways, including the phosphatidylinositide 3-kinase (PI3K)/Akt and p38 MAPK signaling involved in regulating of cell survival, proliferation, migration and differentiation $[40,41]$. c-Kit ${ }^{+} / \mathrm{Lin}^{-} \mathrm{CSCs}$ are present in the early post-natal and adult myocardium of mammals (rodents, pigs, dogs, humans) with a frequency of approximately 1 cell per 10,000 of the total myocytes and higher proportion in the atria and heart apex $[9,19,42,43]$. They cells are multipotent, being able to express the cardiac specific transcription factors including Nkx2.5, Gata4, myocyte enhancer factor 2c (Mef2c) $[44,45]$. These cells can differentiate into mature cardiomyocytes as well as into smooth muscle and endothelial cells both in vitro and in vivo. Their multipotency was further supported by their ability to form cardiospheres [16].

\section{Sca-1 ${ }^{+}$CSCs}

These cells have been characterized by the expression of the stem cell antigen (Sca)-1 in the murine adult heart. The exact counterpart of these cells in the human heart is currently unknown [35]. Sca-1 (or lymphocyte activation protein-6A, Ly6A) is a glycosyl phostidylinositol (GPI)-anchored cell surface protein of the Ly6 gene family, originally described as one of the cell surface markers of hematopoietic stem cells. Sca-1 is localized to lipid rafts where it regulates signaling complexes associated with maintenance and self-renewing of the stem cell compartment [46].

Freshly isolated, Sca- $1^{+}$cells express the early cardiac specific transcription factor Gata4 and Mef2c but not Nkx2.5. They can differentiate into cardiomyocytes after treatment with 5-azacytidine and can form spontaneously beating clusters when exposed to oxytocin in culture $[18,47]$. These cells may give rise to different cell subpopulations: i) Sca- $1^{+} / \mathrm{CD} 31^{-}$cells with a cardiomyocyte and endothelial cell differentiation potential $[48,49]$; ii) $\mathrm{Sca}-1^{+} /$tyrosinekinase platelet-derived growth factor receptor (PDGFR) $\alpha^{+}$cells with a pro-epicardial origin which are located in the perivascular adventitia of the adult heart and are able to generate smooth muscle and endothelial cells $[50,51]$; iii) a small side population (SP) (owing this name to the distinct localization of these cells on flow cytometry analysis as compared to the main population) characterized by an high expression of ATP binding cassette (Abc) transporter family members including the Abc sub-family G member 2 (Abcg2, also known as breast cancer resistance protein $1, \mathrm{Bcrp} 1$ ) and the multidrug resistance protein1(MDR-1) responsible for the unique ability of these cells to efflux DNA binding dyes (that has allowed their identification).

The SP cells are characterized by the low expression of c-Kit, CD34 and CD45 and the lack of CD31, thus excluding their endothelial origin within the heart, and can contribute to diverse cardiac lineages $[21,49,52,53]$.

\section{Isl-1 ${ }^{+}$CSCs}

A population of undifferentiated cells expressing the LIMhomeodomain transcription factor islet- (Isl)-1, the marker for cardiac progenitors of the secondary heart field in the developing heart, has been identified in the newborn and, more recently, also adult heart of rodents and humans, most commonly in the outflow tract, the atria and the right ventricle. Isl- $1^{+}$CSCs represent specific cardiac progenitors conceivably the remnants of primitive cardiomyoblasts. This marker is involved in CSC proliferation and its expression is downregulated as soon as the precursor cells adopt a differentiated cardiac (Nkx2.5, 
Citation: Sassoli C, Orlandini SZ, Bani D, Formigli L (2013) Cardiac Progenitor Cells as Target of Cell and Growth Factor-Based Therapies for Myocardial Regeneration. J Stem Cell Res Ther S9:004. doi:10.4172/2157-7633.S9-004

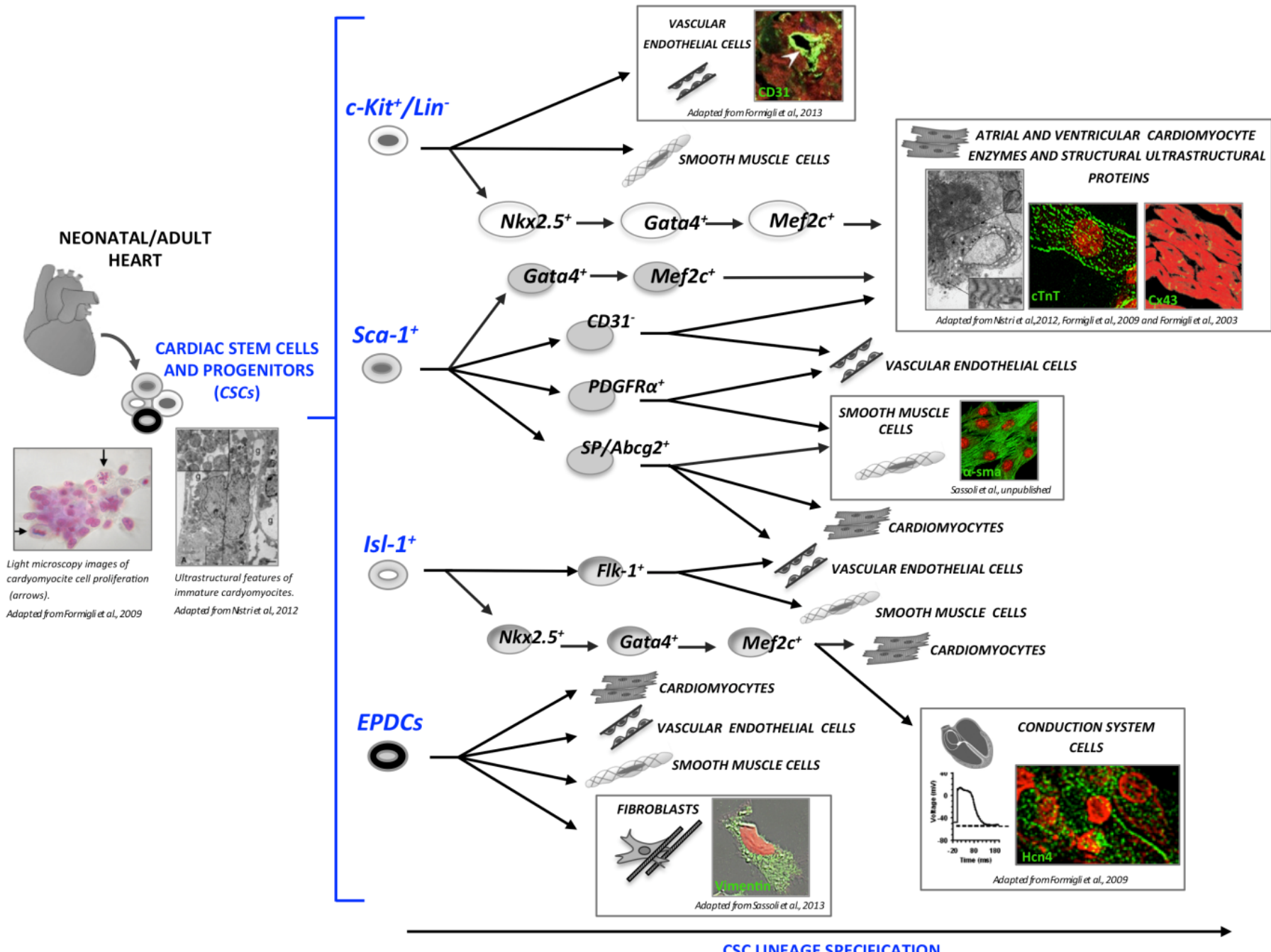

Figure 1: Cardiac stem cells and progenitors (CSCs) and their lineage specifications. Abbreviations: Abcg2: ATP binding cassette transporter sub-family G member 2; c-Kit: Stem Cell Factor; cTnT: Cardiac Troponin T; Cx43: Connexin 43; EDCPs: Epicardium Derived Cells; Hcn4: Hyperpolarization Activated Cyclic Nucleotide-gated Potassium Channel 4 Prominently Expressed in the Pace Maker Region of the Mammalian Heart; Isl-1: LIM-homeodomain Transcription Factor Islet-1; Lin: Markers of the Hematopoietic Lineages; Mef2c: Myocyte Enhancer Factor 2c; PDGFRa: Tyrosine-kinase Platelet-derived Growth Factor Receptor; -sma: -Smooth Muscle Actin; Sca-1: Stem Cell Antigen-1; SP: Side Population. References: [119,120,125,129,130].

Gata4, Mef2c) and vascular phenotype (vascular endothelial growth factor receptor 2, VEGFR2, or the mouse and human counterparts, fetal liver kinase-1, Flk-1 and KDR, respectively) [54-58]. Moreover, Isl- $1^{+}$CSCs do not express $\mathrm{c}-\mathrm{Kit}$ or Sca-1 and are CD31 negative [54]. Moreover lineage tracing experiments have shown that Isl- $1^{+}$ progenitors can contribute also to generate the cardiac conduction system and smooth muscle [55-59].

\section{Epicardium derived cells (EPDCs)}

An increasing number of recent findings indicates that the postnatal and adult mammalian epicardium may represent a source of cardiac progenitors [60-63]. These cardiac progenitor cells represent a subset of epicardial cells which undergoes an epithelial-tomesenchymal transition (EMT) generating a population of epicardium derived cells (EPDCs) which invade the myocardium to differentiate into various cell types, including coronary smooth muscle and endothelial cells, perivascular and cardiac interstitial fibroblasts [6366]. Lineage tracing experiments have demonstrated a contribution of these cells to cardiomyocytes [67-69]. EPDCs are c-Kit negative and Sca-1 positive [69].

\section{Induction of Endogenous Cardiac Repair Mechanisms by Cell Therapy}

\section{Functional benefits of cell therapy on cardiac regeneration}

Myocardial infarction and ischemic cardiomyopathy are typified by the irreversible loss of cardiomyocytes and vasculature, which are essential for maintaining cardiac integrity and function. For this reason, the goal of cardiovascular research has been in the last years, to find methods to repair the damaged myocardium in order to prevent or reverse the pathological cardiac remodeling [70]. In this scenario, stem cell-based therapies aimed at substituting the lost myocytes via trans-differentiation or differentiation of injected exogenous stem cells, have became an attractive and promising experimental treatment for heart disease and failure. Bone marrow-derived mesenchymal stromal cells (MSCs), and, more recently, the endogenous CSCs have emerged 
as leading candidates for cell therapy [14,43,71-74]. Arguments in favor of MSCs include the easy accessibility from the bone marrow and also from the adipose tissue, the great expansion potential in vitro, the presumptive plasticity, the ability to migrate and home at site of injury and the immunosuppressive properties that may allow allogenic transplantation $[75,76]$. In turn, CSCs encompass different cell populations derived from the heart itself, as reported above, which obviously possess superior cardiomyogenic potential in vitro given their involvement in physiological cardiomyocyte turnover $[16,35,43]$. However, the actual use of these cells to repair the damaged myocardium is currently debated, owing to the low-yield, time consuming and expensive procedures of isolation and amplification in vitro [73]. Several of the previous studies have demonstrated the therapeutic benefits of cell-based therapy in numerous animal model, showing that MSC and CSC transplantation in the ischemic heart led to a marked improvement of the ventricular contractile function and ejection fraction, and to a significant amelioration of ventricular remodeling $[14,35,43,71,73]$. Clinical trials using autologous MSCs have also been initiated in humans for both acute myocardial infarction and ischemic cardiomyopathy with preliminary successful results $[71,73,77]$. However, a critical issue of debate in cell-therapy for cardiac regeneration is related with the route of stem cell delivery, as not all methods are suited to provide enough cell engraftment in the damaged organ to be repaired. Basically, the most used delivery techniques include direct injection into the myocardium and intracoronary infusion [78]. Recently, local implantation of biocompatible scaffolds pre-colonized with stem cells has been proposed and used as a promising therapeutic option to improve cell settlement and survival $[79,80]$.

\section{Mechanisms underlying the functional benefits of cell therapy}

At variance with the most logical expectations, recent reports have shown that the beneficial effects of cell therapy, whether MSC- or CSCbased, cannot be attributed to differentiation of the transplanted cells into functional cardiomyocytes. This is not surprising for MSCs, which although expressing Sca-1 like CSCs [81], fail to express the other specific cardiomyogenic markers once engrafted into the host tissue [82]. Instead, it represents an unexpected limitation for CSCs. Most of the engrafted cells, in fact, cannot survive within the host myocardium (the vast majority of the injected cells do not persist several weeks after delivery) and the frequency of true myocardial differentiation is very low compared with the magnitude of the functional repair $[73,74,82-86]$. The recognition of the existence of a pool of endogenous CSCs in the adult heart by a number of independent groups has shifted the attention of many researchers in this field to the ability of the transplanted cells to activate, through juxtacrine/paracrine mechanisms, the host's intrinsic reparative processes. In particular, by using dual labeling with GFP and sex mismatch strategies, it has been demonstrated that the injection of allogenic porcine MSCs into the infarcted areas of pig hearts promotes cardiac regeneration by augmenting the formation of new cardiomyocytes from the endogenous $\mathrm{c}-\mathrm{Kit}^{+}$precursors [87]. Moreover, the intracoronary injection of autologous MSCs into pigs with hibernating myocardium, have been reported to stimulate the proliferation of the resident c-Kit ${ }^{+} \mathrm{CSCs}$ and the mobilization of endogenous precursors from the extra-cardiac sources, such as bone marrow [88]. We have recently demonstrated that mouse bone marrow-derived MSCs co-cultured with mouse neonatal cardiomyocytes are capable of stimulating cardiomyocytes proliferation, through the activation of the Notch-1/Jagged1 pathway [89]. Recent findings suggest that even when autologous or syngenic CSCs are used, direct differentiation is not the primary mechanisms by which these cells promote cardiac repair/regeneration responsible for the functional improvements [14]. This assumption is based on the data showing the intracoronary infusion of GFP-labelled adult CSCs in a model of chronic myocardial infarction stimulate endogenous CSC proliferation, a phenomenon which persists even after the transplanted cells had disappeared [90]. In addition, direct differentiation of cardiospheres derived from adult hearts have been demonstrated to account for a $30 \%$ up to $50 \%$ of the regenerative response observed after the injection of these cells in the infarct border zones of immuodeficient mice [91]. Based on these findings, studies from our group and others have tried to identify the paracrine factors that could mediate cardiac repair/regeneration $[71,73,89,92-94]$. It has been found that MSCs produce and secrete a broad repertoire of trophic factors and cytokines, including fibroblast growth factor (FGF), VEGF, hepatocyte growth factor (HGF), Insulin growth factor (IGF-1), stem cell-derived factor (SDF)-1, interleukin (IL)-6, which have been reported to drive the regeneration of injured hearts, being capable of recreating a suitable microenvironment for cardiac repair, protecting the ischemic myocytes from apoptosis [95], inhibiting the inflammatory response, stimulating neo-angiogenesis and extracellular matrix (ECM) remodeling [71] and potentiating the endogenous self repair mechanisms (Figure 2) $[89,94,96,97]$. Interestingly, the release of these factors is enhanced in response to stress or inflammation [98-100]. Furthermore, recent data indicate that MSCs and CSCs can release microparticles and exosomes containing paracrine signals and micro-RNAs, which can influence the regenerative process through mechanisms not completely understood [77,101]. The paracrine action of the transplanted cells on cardiac repair has been further supported by the data showing that the extra-cardiac injection of MSCs into the skeletal muscle was capable of significantly improving the ventricular functions and promote cardiac regeneration in the hamster, despite the fact that the injected cells were trapped into the remote musculature [102]. It is important to point out that the simple administration of MSC-conditioned medium may not have the same impact as the injection of the cells. In fact, in a swine model of myocardial infarction, the single application of concentrated conditioned media was unable to recruit $\mathrm{c}-\mathrm{Kit}^{+} \mathrm{CSCs}$ and reduce the infarct size, whereas injection of MSC was [87]. Moreover, the administration of human bone-marrow derived endothelial progenitor cells into mice after myocardial infarction, elicited a significant elevation of circulating factors involved in angiogenesis, anti-apoptosis effect, proliferation of host cardiomyocytes and chemoattraction. The majority of these factors was of murine origin and was found at high level in the injured myocardium after 14 days, a time point at which most of the injected cells had disappeared [103]. These data indicate that sustained release of paracrine factors could be attributed to the interaction between the transplanted cells and the host cells and tissues, which explain the persistence of the paracrine response.

\section{Induction of Endogenous Cardiac Repair Mechanisms by Growth Factors and Cardiotropic Hormones}

\section{Growth factors}

The proper spatio-temporal delivery of cardiotropic growth factors and hormones may also represent a major option in the therapeutic strategies to induce myocardial regeneration after an ischemic event (Figure 2). This approach may have, at least conceptually, some advantages over those based on cell transplantation, consisting mainly in availability "off-the-shelf" and easy application. Among these factors, the positive effects on myocardial repair of IGF-1and HGF have been extensively demonstrated $[104,105]$. Indeed, the cytoprotective and proliferative effects of IGF-1, the major growth hormone effector, together with the pro-angiogenic and anti-fibrotic properties of 
Citation: Sassoli C, Orlandini SZ, Bani D, Formigli L (2013) Cardiac Progenitor Cells as Target of Cell and Growth Factor-Based Therapies for Myocardial Regeneration. J Stem Cell Res Ther S9:004. doi:10.4172/2157-7633.S9-004

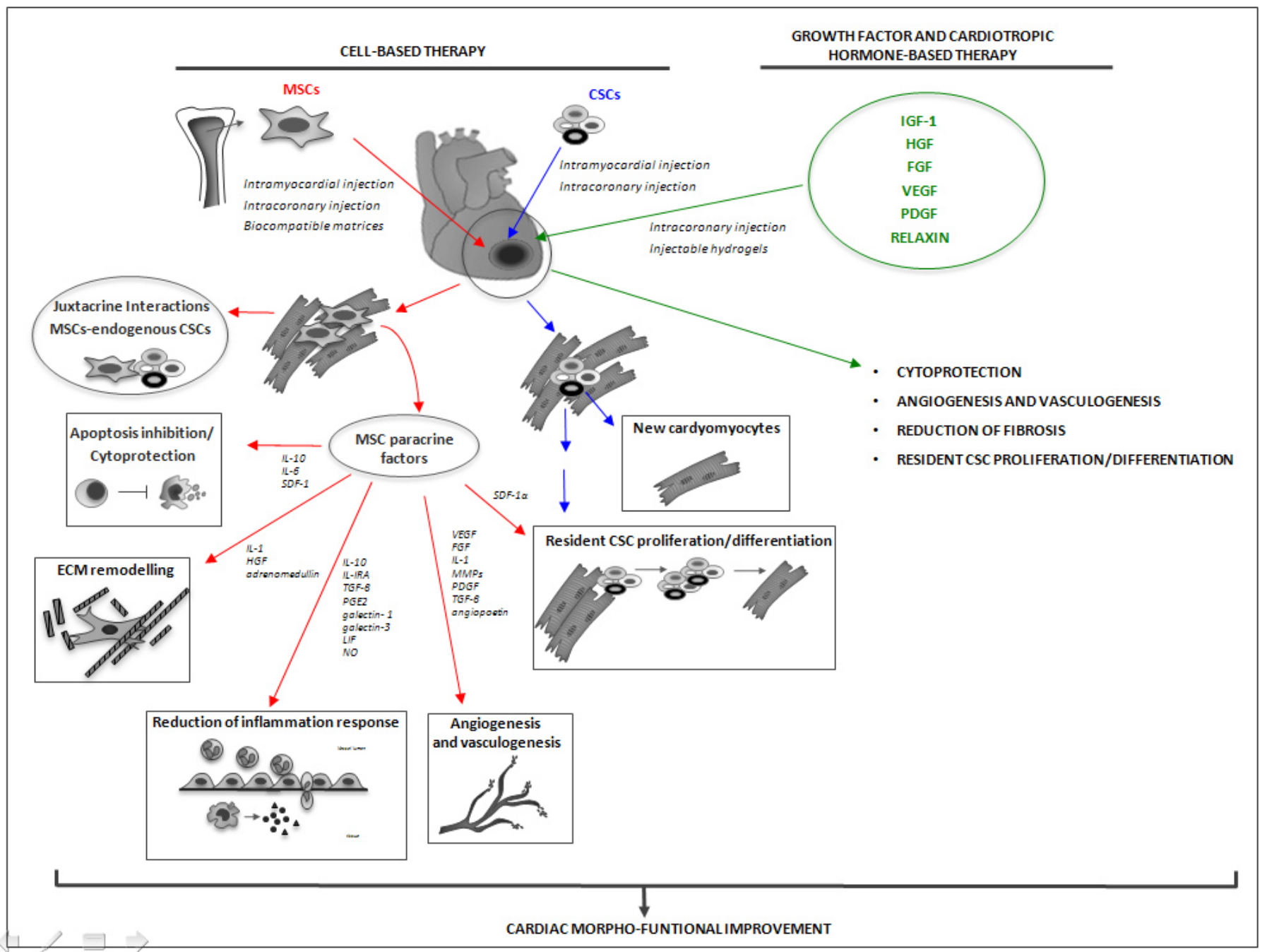

Figure 2: Schematic representation of the relevant mechanisms underlying the functional benefits of MSC-and CSC-and growth factor/cardiotropic hormonebased therapy. Abbreviations: CSCs: Cardiac Stem/Progenitor Cells; ECM: Extracellular Matrix; FGF: Fibroblast Growth Factor; HGF: Hepatocyte Growth Factor; IGF-1: Insulin Growth Factor-1; IL-1: Interleukin 1; IL 6: Interleukin-6; IL-10: Interleukin-10; IL-1RA: Interleukin 1 Receptor Antagonist; LIF: Leukemia Inhibitory Factor; MMPs: Matrix Metalloproteinases; MSCs: Mesenchymal Stromal Cells; NO: Nitric Oxide; PDGF: Platelet Derived Growth Factor; PGE2: Prostaglandin E2; SDF-1: Stromal Derived Factor-1; TGF- $\beta$ : Transforming Growth Factor- $\beta$; VEGF: Vascular Endothelial Growth Factor.

HGF, have been shown to constitute a powerful combination, which addresses various aspects of myocardial regeneration. In particular, the intracoronary administration of the two growth factors in pigs with acute myocardial infarction, have been shown to effectively reduce adverse pathological cardiac remodeling and improve the regenerative response of c-Kit ${ }^{+}$CSCs [106]. Similar results have been obtained whit FGF and IGF-1 delivered in the rat ischemic myocardium by means of injectable hydrogels, designed to reduce their systemic spread and maximize their local therapeutic effect [107]. This technique has also been proven to be an optimal approach to increase therapeutic neo-angiogenesis in the damaged myocardium. Local delivery of VEGF, the major mediator of angiogenesis [108], and PDGF, which stimulates the recruitment of smooth muscle cells into newly formed vessels [109], endowed into alginate hydrogels after myocardial infarction induced better remodeling of the vasculature and improvement of cardiac function as compared to the untreated animals or those treated with simple or combined growth factor solutions [110]. Despite their effectiveness, the administration of growth factors has been shown to have some limitations. In a study conducted by Ellison and co-workers [106] it has been reported that the cardiomyocytes generated in response to growth factor administration in the infarcted pig myocardium, are immature and have limited force-generating capacity, allowing to conclude that the documented beneficial effects on ventricular performance are likely due to other mechanisms than cardiac regeneration, including decreased cardiomyocyte loss and improved ventricular remodeling. Moreover, the single transendocardial injection of concentrated conditioned media from MSCs in a swine model of acute myocardial infarction may not able to reduce infarct size and recruit endogenous c-Kit ${ }^{+}$CSCs [87].

\section{Relaxin}

Among the cardiotropic hormones, which have been studied for heart regenerative purposes, relaxin (RLX) definitely deserves to be mentioned. RLX belongs to the relaxin peptide family of structurallyrelated hormones, which in humans encompasses RLX H1, H2 and $\mathrm{H} 3$ as well as insulin-like peptides (INSL-) 3 to 6 [111]. Of these, 
RLX H2 is the main circulating bioactive hormone. Best known for its physiological roles during pregnancy, it is increasingly recognized as a cardiotropic hormone, being produced by the heart and acting on specific heart receptors [111-113]. Experimental findings from animal models and clinical trials suggest that RLX is effective in the protection and/or treatment of the failing heart. Our research group has demonstrated that this hormone can effectively blunt myocardial damage in experimentally induced acute myocardial infarction in various species of laboratory mammals [114-117], and can be a valid adjuvant for precursor cell grafting to repair the post-infarct myocardium in swine [118]. In these studies, RLX was able to improve left ventricular performance and contractility, induce profound modifications of the elastic and trophic properties of the ischemic scar, up-regulate MMPs expression and increase neo-angiogenesis in the ischemic area and the surrounding stunned myocardium. We have also shown that RLX, besides contributing to the recreation of a suitable microenvironment for cardiac repair, was able to stimulate the cardiomyogenic potential of cardiac progenitor cells $[119,120]$. This notion is supported by a series of matching findings. We first showed that mouse neonatal cardiomyocytes in culture grew forming spontaneously beating clusters which were connected by bridgelike structures represented by elongated cells, likely of stromal origin. Interestingly, these cells were functionally coupled with the cardiomyocytes of the clusters by $\mathrm{Cx} 43$-positive gap-junctions, which allowed the exchange of signals among the adjacent clusters. These features are suggestive of a complex communication system that could serve to coordinate cardiomyocytes development among different clusters and mediate their compaction to form a functional myocardium similarly to embryonic cardiomyogenesis [121]. The addition of RLX to this cell system increased the number of connecting cells and enhanced the growth and differentiation attitude of the myocardial precursors in the clusters. Then, we found that RLX was able to stimulate mouse cardiomyocyte differentiation in vitro and support their maturation towards a functional phenotype, through its direct interaction with specific receptors expressed by the cardiomyocytes [120]. Along this line of evidence, the widely reported antifibrotic effect of RLX [122125] can play a substantial role, as it may facilitate the mobilization and expansion of CSCs through the reduction of collagen fiber density in the myocardial scar $[118,126]$. Cardiac extracellular matrix softening and improved post-ischemic remodeling can therefore represent an additional mechanism by which RLX may support the endogenous regenerative potential of the adult heart.

\section{Conclusions and Future Directions}

Cell therapy is currently considered as a promising approach for repairing the damaged myocardium. Originally proposed as a way for replacing the dead cardiomyocytes with new cells capable of restoring the contractile function in the ischemic scar, the rationale of its therapeutic use has been shifted towards the paracrine secretion of cardiotropic factors by the transplanted cells on the host myocardial tissue, capable of stimulating the endogenous CSCs. This idea has lead to the development of preclinical studies in which myocardial repair/ regeneration has been achieved by the administration of concentrated conditioned medium from MSCs or CSCs. Despite an undoubted value as a proof-of-concept, these studies have some practical limitations, mainly consisting in a rapid systemic redistribution of the injected paracrine factors, their inability to induce the formation of contractile cells and the need for repeated local inoculations to reduce scar size and activate the heart's endogenous reparative processes. On the other hand, it is likely that the better therapeutic efficacy of cell transplantation over growth factor administration may be related to ability of the injected cells to engraft into the diseased heart, where they locally deliver a complex mixture of paracrine factors. Another advantage of cell therapy may be related to the ability of the engrafted cells to also establish juxtacrine interactions with endogenous CSCs. This is conceivable based on the observations that stromal cells can act as supporting cells that, through direct cell-to-cell interactions, are capable of guiding the compaction of myocardial trabecolae during the embryonic heart development and the clustering of cardiomyocyte aggregates in vitro to form a functional myocardium. However, the major limitation of cell therapy consists in the fact that the engrafted cells only transiently survive within the recipient myocardium. To overcome this hurdle, the cells to be transplanted could be used in combination with added growth factors, or genetically modified ex vivo prior to administration to enhance the expression of genes, which can improve their survival, engraftment potential and therapeutic efficacy after delivery. Basically, there are two pathways pointing at this aim, i.e. increasing local vascularization and blood supply to improve the recipient microenvironment, and enhancing the intrinsic survival capability of the grafted cells. Both goals can be achieved by genetic manipulation or supplementation of proangiogenic, anti-apoptotic and preconditioning agents $[127,128]$. Future studies are definitely required to check these working hypotheses and carefully evaluate its translational potential for regenerative medicine. However, research in this exciting field will likely provide major insight into the cellular and molecular mechanisms underlying cardiomyocyte regeneration.

\section{References}

1. Rosamond W, Flegal K, Friday G, Furie K, Go A, et al. (2007) Heart disease and stroke statistics-2007 update: a report from the American Heart Association Statistics Committee and Stroke Statistics Subcommittee. Circulation 115: e69171.

2. Diwan A, Dorn GW 2nd (2007) Decompensation of cardiac hypertrophy: cellular mechanisms and novel therapeutic targets. Physiology 22: 56-64.

3. Swedberg K, Cleland J, Dargie H, Drexler H, Follath F, et al. (2005) Guidelines for the Diagnosis and Treatment of Chronic Heart Failure: executive summary (update 2005): the task force for the diagnosis and treatment of chronic heart failure of the European Society of Cardiology. Eur Heart J 26: 1115-1140.

4. Poss KD, Wilson LG, Keating MT (2011) Heart regeneration in zebrafish Science 298: 2188-2190.

5. Schnabel K, Wu CC, Kurth T, Weidinger G (2011) Regeneration of cryoinjury induced necrotic heart lesions in zebrafish is associated with epicardial activation and cardiomyocyte proliferation. PLoS One 6: e18503.

6. Singh BN, Koyano-Nakagawa N, Garry JP, Weaver CV (2010) Heart of newt: a recipe for regeneration. J Cardiovasc Transl Res 3: 397-409.

7. Kühl SJ, Kühl M (2011) Improving cardiac regeneration after injury: are we a step closer? Bioessays 33: 669-673.

8. Slack JMW (2003) Regeneration research today. Dev Dyn 226: 162-166.

9. Urbanek K, Torella D, Sheikh F, De Angelis A, Nurzynska D, et al. (2005) Myocardial regeneration by activation of multipotent cardiac stem cells in ischemic heart failure. Proc Natl Acad Sci USA 102: 8692-8697.

10. Torella D, Ellison GM, Nadal-Ginard B, Indolfi C (2005) Cardiac stem and progenitor cell biology for regenerative medicine. Trends Cardiovasc Med 15: 229-236.

11. Urbanek K, Cesselli D, Rota M, Nascimbene A, De Angelis A, et al. (2006) Stem cell niches in the adult mouse heart. Proc Natl Acad Sci USA 103: 92269231.

12. Torella D, Ellison GM, Méndez-Ferrer S, Ibanez B, Nadal-Ginard B (2006) Resident human cardiac stem cells: role in cardiac cellular homeostasis and potential for myocardial regeneration. Nat Clin Pract Cardiovasc Med 3: S8-13.

13. Anversa P, Kajstura J, Leri A, Bolli R (2006) Life and death of cardiac stem cells: a paradigm shift in cardiac biology. Circulation 113: 1451-1463.

14. Barile L, Messina E, Giacomello A, Marbán E (2007). Endogenous cardiac stem cells. Prog Cardiovasc Dis 50: 31-48. 
Citation: Sassoli C, Orlandini SZ, Bani D, Formigli L (2013) Cardiac Progenitor Cells as Target of Cell and Growth Factor-Based Therapies for Myocardial Regeneration. J Stem Cell Res Ther S9:004. doi:10.4172/2157-7633.S9-004

15. Ellison GM, Galuppo V, Vicinanza C, Aquila I, Waring CD, et al. (2010) Cardiac stem and progenitor cell identification: different markers for the same cell? Front Biosci (Schol Ed). 2: 641-652.

16. Leri A, Kajstura J, Anversa P (2011) Role of cardiac stem cells in cardiac pathophysiology: a paradigm shift in human myocardial biology. Circ Res 109: 941-961.

17. He JQ, Vu DM, Hunt G, Chugh A, Bhatnagar A, et al. (2011) Human cardiac stem cells isolated from atrial appendages stably express c-Kit. PLoS One. 6:e27719.

18. Oh H, Bradfute SB, Gallardo TD, Nakamura T, Gaussin V, et al. (2003) Cardiac progenitor cells from adult myocardium: homing, differentiation, and fusion after infarction. Proc Natl Acad Sci USA 100: 12313-12318.

19. Beltrami AP, Barlucchi L, Torella D, Baker M, Limana F, et al. (2003) Adult cardiac stem cells are multipotent and support myocardial regeneration. Cell 114: 763-776.

20. Müller P, Beltrami AP, Cesselli D, Pfeiffer P, Kazakov A, et al. (2005) Myocardial regeneration by endogenous adult progenitor cells. J Mol Cell Cardiol 39: 377 387.

21. Oyama T, Nagai T, Wada H, Naito AT, Matsuura K, et al. (2007) Cardiac side population cells have a potential to migrate and differentiate into cardiomyocytes in vitro and in vivo. J Cell Biol 176: 329-341.

22. Anversa P, Leri A, Rota M, Hosoda T, Bearzi C, et al. (2007) Concise review: stem cells, myocardial regeneration, and methodological artifacts. Stem Cells 25:589-601.

23. Leri A, Kajstura J, Anversa P, Frishman WH (2008) Myocardial regeneration and stem cell repair. Curr Probl Cardiol 33: 91-153.

24. Lyngbaek S, Schneider M, Hansen JL, Sheikh SP (2007) Cardiac regeneration by resident stem and progenitor cells in the adult heart. Basic Res Cardiol 102 . 101-14.

25. Guan K, Hasenfuss G (2007) Do stem cells in the heart truly differentiate into cardiomyocytes? J Mol Cell Cardiol 43: 377-387.

26. Doljanski $F$ (2004) The sculpturing role of fibroblast-like cells in morphogenesis. Perspect Biol Med 47: 339-356.

27. Popescu LM, Gherghiceanu M, Manole CG, Pellegrini-Faussone MS (2009) Cardiac renewing: interstitial Cajal-like cells nurse cardiomyocyte progenitors in epicardial stem cell niches. J Cell Mol Med 13: 866-886.

28. Bani D, Formigli L, Gherghiceanu M, Faussone Pellegrini S (2010) Telocytes as supporting cells for myocardial tissue organization in developing and adult heart. J Cell Mol Med 14: 2531-2538.

29. Yoshida Y, Yamanaka S (2011) iPS cells: a source of cardiac regeneration $J$ Mol Cell Cardiol 50: 327-32

30. Quattrocelli M, Thorrez L, Sampaolesi M (2013) Pluripotent stem cell derivation and differentiation toward cardiac muscle: novel techniques and advances in patent literature. Recent Pat Drug Deliv Formul 7: 18-28.

31. Mauritz C, Martens A, Rojas SV, Schnick T, Rathert C, et al. (2011) Induced pluripotent stem cell (iPSC)-derived Flk-1 progenitor cells engraft, differentiate, and improve heart function in a mouse model of acute myocardial infarction. Eur Heart J 32: 2634-41.

32. Kao RL, Ganote CE, Pennington DG, Browder IW (2007) Myocardial regeneration, tissue engineering and therapy. In: Prakash S. Artificial cells, cell engineering and therapy. 1st ed. Woodhead Publishing Ltd, Cambridge, England 349-65.

33. Prockop DJ, Olson SD (2007) Clinical trials with adult stem/progenitor cells for tissue repair: let's not overlook some essential precautions. Blood 109: 31473151.

34. Segers VF, Lee RT (2008) Stem-cell therapy for cardiac disease. Nature 451: 937-942.

35. Chong JJ (2012) Cell therapy for left ventricular dysfunction: an overview for cardiac clinicians. Heart Lung Circ 21: 532-542.

36. Kuhn EN, Wu SM (2010) Origin of cardiac progenitor cells in the developing and postnatalheart. J Cell Physiol 225: 321-325.

37. Dey D, Han L, Bauer M, Sanada F, Oikonomopoulos A, et al. (2013) Dissecting the Molecular Relationship Among Various Cardiogenic Progenitor Cells. Circ Res 112: 1253-1262.
38. Messina E, De Angelis L, Frati G, Morrone S, Chimenti S, et al. (2004) Isolation and expansion of adult cardiac stem cells from human and murine heart. Circ Res 95: 911-921.

39. Chimenti I, Gaetani R, Barile L, Forte E, Ionta V, et al. (2012) Isolation and expansion of adult cardiac stem/progenitor cells in the form of cardiospheres from human cardiac biopsies and murine hearts. Methods Mol Biol 879: $327-$ 338.

40. Edling CE, Hallberg B (2007) c-Kit, a hematopoietic cell essential receptor tyrosine kinase Int J Biochem Cell Biol 39 :1995-1998

41. Kuang D, Zhao X, Xiao G, Ni J, Feng Y, et al. (2008) Stem cell factor/c-kit signaling mediated cardiac stem cell migration via activation of p38 MAPK. Basic Res Cardiol. 2008 103: 265-73.

42. Linke A, Müller P, Nurzynska D, Casarsa C, Torella D, et al. (2005) Stem cells in the dog heart are self-renewing, clonogenic, and multipotent and regenerate infarcted myocardium, improving cardiac function. Proc Natl Acad Sci U S A 102: 8966-8971.

43. Bearzi C, Rota M, Hosoda T, Tillmanns J, Nascimbene A, et al. (2007) Human cardiac stem cells. Proc Natl Acad Sci U S A 104: 14068-14073.

44. Molkentin JD, Lin Q, Duncan SA, Olson EN (1997) Requirement of the transcription factor GATA4 for heart tube formation and ventral morphogenesis. Genes Dev 11:1061-1072.

45. Lin Q, Schwarz J, Bucana C, Olson EN (1997) Control of mouse cardiac morphogenesis and myogenesis by transcription factor MEF2C. Science 276 1404-1407.

46. Holmes C, Stanford WL (2007) Concise review: stem cell antigen-1: expression function, and enigma. Stem Cells 25: 1339-1347.

47. Matsuura K, Nagai T, Nishigaki N, Oyama T, Nishi J, et al. (2004) Adult cardiac Sca-1-positive cells differentiate into beating cardiomyocytes. J BiolChem 279 11384-11391.

48. Wang X, Hu Q, Nakamura Y, Lee J, Zhang G, et al. (2006) The role of the sca$1+/ C D 31-$ cardiac progenitor cell population in post infarction left ventricular remodeling. Stem Cells 24: 1779-1788.

49. Liang SX, Tan TY, Gaudry L, Chong B (2010) Differentiation and migration of Sca1+/CD31- cardiac side population cells in a murine myocardial ischemic model. Int J Cardiol 138: 40-49.

50. Chong JJ, Chandrakanthan V, Xaymardan M, Asli NS, Li J, et al. (2011) Adult cardiac-resident MSC-like stem cells with a proepicardial origin. Cell Stem Cell 9: 527-540.

51. Chong JJ, Reinecke H, Iwata M, Torok-Storb B, Stempien-Otero A, et al. (2013) Progenitor Cells Identified by PDGFR-Alpha Expression in the Developing and Diseased Human Heart. Stem cell Dev [Epub ahead of print]

52. Martin CM, Meeson AP, Robertson SM, Hawke TJ, Richardson JA, et al. (2003) Persistent expression of the ATP-binding cassette transporter, Abcg2, identifies cardiac SP cells in the developing and adult heart. Dev Biol 265: 262-275.

53. Unno K, Jain M, Liao R (2012) Cardiac side population cells: moving toward the center stage in cardiac regeneration. Circ Res 110:1355-1363.

54. Laugwitz KL, Moretti A, Lam J, Gruber P, Chen Y, et al. (2005) Postnatal isI $1^{+}$ cardioblasts enter fully differentiated cardiomyocyte lineages. Nature 433: 647653.

55. Moretti A, Caron L, Nakano A, Lam JT, Bernshausen A, et al. (2006) Multipotent embryonic isl1+ progenitor cells lead to cardiac, smooth muscle, and endothelial cell diversification. Cell 127: 1151-1165.

56. Genead R, Danielsson C, Andersson AB, Corbascio M, Franco-Cereceda A, et al. (2010) Islet-1 cells are cardiac progenitors present during the entire lifespan: from the embryonic stage to adulthood. Stem Cells Dev 19:1601-1615.

57. Weinberger F, Mehrkens D, Friedrich FW, Stubbendorff M, Hua X, et al. (2012) Localization of Islet-1-positive cells in the healthy and infarcted adult murine heart. Circ Res 110:1303-1310.

58. Moretti A, Lam J, Evans SM, Laugwitz KL (2007) Biology of IsI1+ cardiac progenitor cells in development and disease. Cell Mol Life Sci 64: 674-682.

59. Barzelay A, Ben-Shoshan J, Entin-Meer M, Maysel-Auslender S, Afek A, et al (2010) A potential role for islet-1 in post-natalangiogenesis and vasculogenesis. Thromb Haemost 103: 188-197.

60. Limana F, Zacheo A, Mocini D, Mangoni A, Borsellino G, et al. (2007) 
Identification of myocardial and vascular precursor cells in human and mouse epicardium. Circ Res 101: 1255-1265.

61. Gittenberger-de Groot AC, Winter EM, Poelmann RE (2010) Epicardiumderived cells (EPDCs) in development, cardiac disease and repair of ischemia. J Cell Mol Med 14:1056-1060.

62. Singh MK, Epstein JA (2012) Epicardium-derived cardiac mesenchymal stem cells: expanding the outer limit of heart repair. Circ Res 110: 904-906.

63. Smart N, Dubé KN, Riley PR (2013) Epicardial progenitor cells in cardiac regeneration and neovascularisation. Vascul Pharmacol 58:164-173.

64. van Tuyn J, Atsma DE, Winter EM, van der Velde-van Dijke I, Pijnappels DA et al. (2007) Epicardial cells of human adults can undergo an epithelial-tomesenchymal transition and obtain characteristics of smooth muscle cells in vitro. Stem Cells. 25:271-278.

65. Urayama K, Guilini C, Turkeri G, Takir S, Kurose H, et al. (2008) Prokineticin receptor-1 induces neovascularization and epicardial-derived progenitor cell differentiation. Arterioscler Thromb Vasc Biol 28: 841-849.

66. Smart N, Riley PR (2009) Derivation of epicardium-derived progenitor cells (EPDCs) from adult epicardium. Curr Protoc Stem Cell Biol Chapter 2: Unit2C.2.

67. Cai CL, Martin JC, Sun Y, Cui L, Wang L, et al. (2008) A myocardial lineage derives from Tbx18 epicardial cells. Nature 454:104-108.

68. Zhou B, Ma Q, Rajagopal S, Wu SM, Domian I, et al. (2008) Epicardial progenitors contribute to the cardiomyocyte lineage in the developing heart. Nature 454: 109-113.

69. Smart N, Bollini S, Dubé KN, Vieira JM, Zhou B, et al. (2011) De novo cardiomyocytes from within the activated adult heart after injury. Nature 474 : 640-644.

70. van den Borne SW, Diez J, Blankesteijn WM, Verjans J, Hofstra L, et al. (2010) Myocardial remodeling after infarction: the role of myofibroblasts. Nat Rev Cardiol 7: 30-37.

71. Williams AR, Hare JM (2011) Mesenchymal stem cells: biology, pathophysiology, translational findings, and therapeutic implications for cardiac disease. Circ Res 109: 923-940.

72. Copland IB (2011) Mesenchymal stromal cells for cardiovascular disease. Cardiovasc Dis Res 2: 3-13

73. Sassoli C, Zecchi-Orlandini S, Formigli L (2012) Trophic Actions of Bone Marrow-Derived Mesenchymal Stromal Cells for Muscle Repair/Regeneration Cells 1: 832-850.

74. Tang YL, Wang YJ, Chen LJ, Pan YH, Zhang L, et al. (2013) Cardiac-derived stem cell-based therapy for heart failure: progress and clinical applications. Exp Biol Med 238: 294-300.

75. Vono R, Spinetti G, Gubernator M, Madeddu P (2012) What's new in regenerative medicine: split up of the mesenchymal stem cell family promises new hope for cardiovascular repair. J Cardiovasc Transl Res 5: 689-699.

76. Le Blanc, K, Mougiakakos, D (2012) Multipotent mesenchymal stromal cells and the innate immune system. Nat Rev Immunol 12: 383-396.

77. Barile L, Gherghiceanu M, Popescu LM, Moccetti T, Vassalli G (2012) Ultrastructural evidence of exosome secretion by progenitor cells in adult mouse myocardium and adult human cardiospheres. J Biomed Biotechno 2012: 354605

78. Dimmeler S, Burchfield J, Zeiher AM (2008) Cell-based therapy of myocardial infarction. Arterioscler Thromb Vasc Biol 28: 208-216.

79. Martino S, D’Angelo F, Armentano I, Kenny JM, Orlacchio A (2012) Stem cellbiomaterial interactions for regenerative medicine. Biotechnol Adv 2012 30: $338-351$

80. Rustad KC, Wong VW, Sorkin M, Glotzbach JP, Major MR, et al. (2012) Enhancement of mesenchymal stem cell angiogenic capacity and stemness by a biomimetic hydrogel scaffold. Biomaterials 33: 80-90.

81. Houlihan DD, Mabuchi Y, Morikawa S, Niibe K, Araki D, et al. (2012) Isolation of mouse mesenchymal stem cells on the basis of expression of Sca-1 and PDGFR- $\alpha$. Nat Protoc 7: 2103-2111.

82. Siegel G, Krause P, Wöhrle S, Nowak P, Ayturan M, et al. (2012) Bone marrowderived human mesenchymal stem cells express cardiomyogenic proteins but do not exhibit functional cardiomyogenic differentiation potential. Stem Cells Dev 21: $2457-2470$.
83. Murry CE, Soonpaa MH, Reinecke $\mathrm{H}$, Nakajima $\mathrm{H}$, Nakajima $\mathrm{HO}$, et al. (2004) Haematopoietic stem cells do not transdifferentiate into cardiac myocytes in myocardial infarcts. Nature 428: 664-668.

84. Tang YL, Zhao Q, Qin X, Shen L, Cheng L, et al. (2005) Paracrine action enhances the effects of autologous mesenchymal stem cell transplantation on vascular regeneration in rat model of myocardial infarction. Ann Thorac Surg 80: $229-236$

85. Quevedo HC, Hatzistergos KE, Oskouei BN, Feigenbaum GS, Rodriguez JE et al. (2009) Allogeneic mesenchymal stem cells restore cardiac function in chronic ischemic cardiomyopathy via trilineage differentiating capacity. Proc Natl Acad Sci U S A 106:14022-14027.

86. Tang J, Wang J, Guo L, Kong X, Yang J, et al. (2010) Mesenchymal stem cells modified with stromal cell-derived factor 1 alpha improve cardiac remodeling via paracrine activation of hepatocyte growth factor in a rat model of myocardial infarction. Mol Cells 29: 9-19.

87. Hatzistergos KE, Quevedo H, Oskouei BN, Hu Q, Feigenbaum GS, et al. (2010) Bone marrow mesenchymal stem cells stimulate cardiac stem cell proliferation and differentiation. Circ Res 107: 913-922.

88. Suzuki G, lyer V, Lee TC, Canty JM Jr (2011) Autologous mesenchymal stem cells mobilize cKit+ and CD133+ bone marrow progenitor cells and improve regional function in hibernating myocardium. Circ Res 109: 1044-1054.

89. Sassoli C, Pini A, Chellini F, Mazzanti B, Nistri S, et al. (2012) Bone Marrow Mesenchymal Stromal Cells Stimulate Skeletal Myoblast Proliferation through the Paracrine Release of VEGF. PLoS One 7: e37512.

90. Tang XL, Rokosh G, Sanganalmath SK, Yuan F, Sato H, et al. (2010) Intracoronary administration of cardiac progenitor cells alleviates left ventricula dysfunction in rats with a 30-day-old infarction. Circulation 121: 293-305

91. Chimenti I, Smith RR, Li TS, Gerstenblith G, Messina E, et al. (2010) Relative roles of direct regeneration versus paracrine effects of human cardiospherederived cells transplanted into infarcted mice. Circ Res 106: 971-980.

92. Caplan Al, Dennis JE (2006) Mesenchymal stem cells as trophic mediators. $J$ Cell Biochem 98: 1076-1084

93. Gnecchi M, Zhang Z, Ni A, Dzau VJ (2008) Paracrine mechanisms in adult stem cell signaling and therapy. Circ Res 103: 1204-1219.

94. Sassoli C, Pini A, Mazzanti B, Quercioli F, Nistri S, et al. (2011) Mesenchymal stromal cells affect cardiomyocyte growth through juxtacrine Notch-1/Jagged-1 signaling and paracrine mechanisms: clues for cardiac regeneration. J Mol Cell Cardiol 51: 399-408.

95. Gnecchi M, He H, Liang OD, Melo LG, Morello F et al. (2005) Paracrine action accounts for marked protection of ischemic heart by Akt-modified mesenchymal stem cells. Nat Med 11: 367-368.

96. Nakanishi C, Yamagishi M, Yamahara K, Hagino I, Mori H, et al. (2008) Activation of cardiac progenitor cells through paracrine effects of mesenchymal stem cells. Biochem Biophys Res Commun 374:11-16.

97. Loffredo FS, Steinhauser ML, Gannon J, Lee RT (2011) Bone marrow-derived cell therapy stimulates endogenous cardiomyocyte progenitors and promotes cardiac repair. Cell Stem Cell 8: 389-398.

98. Gnecchi M, He H, Noiseux N, Liang OD, Zhang L, et al. (2006) Evidence supporting paracrine hypothesis for Akt-modified mesenchymal stem cellmediated cardiac protection and functional improvement. FASEB J 20: 661 669

99. Lee RH, Oh JY, Choi H, Bazhanov N (2011) Therapeutic factors secreted by mesenchymal stromal cells and tissue repair. J Cell Biochem 112: 3073-3078.

100. Shi C (2012) Recent progress toward understanding the physiological function of bone marrow mesenchymal stem cells. Immunology136: 133-138.

101. Lai RC, Arslan F, Lee MM, Sze NS, Choo A, et al. (2010) Exosome secreted by MSC reduces myocardial ischemia/reperfusion injury. Stem Cell Res 4 214-222.

102. Shabbir A, Zisa D, Leiker M, Johnston C, Lin H, et al. (2009) Muscula dystrophy therapy by non autologous mesenchymal stem cells: muscle regeneration without immunosuppression and inflammation. Transplantation 87: 1275-1282.

103. Cho HJ, Lee N, Lee JY, Choi YJ, li M, et al. (2007) Role of host tissues fo sustained humoral effects after endothelial progenitor cell transplantation into the ischemic heart. J Exp Med 204: 3257-3269. 
Citation: Sassoli C, Orlandini SZ, Bani D, Formigli L (2013) Cardiac Progenitor Cells as Target of Cell and Growth Factor-Based Therapies for Myocardial Regeneration. J Stem Cell Res Ther S9:004. doi:10.4172/2157-7633.S9-004

104. Wang Y, Ahmad N, Wani MA, Ashraf M (2004) Hepatocyte growth factor prevents ventricular remodeling and dysfunction in mice via Akt pathway and angio- genesis. J Mol Cell Cardiol 37:1041e52.

105. Suleiman MS, Singh RJ, Stewart CE (2007) Apoptosis and the cardiac action of insulin-like growth factor I. Pharmacol Ther 114: 278e94

106. Ellison GM, Torella D, Delle grottaglie S, Perez-Martinez C, Perez de Prado A, et al. (2011) Endogenous cardiac stem cell activation by insulin-like growth factor-1/hepatocyte growth factor intracoronary injection fosters survival and regeneration of the infarcted pig heart. J Am Coll Cardiol 58: 977-986.

107. Ruvinov E, Leor J, Cohen S (2011) The promotion of myocardial repair by the sequential delivery of IGF- 1 and HGF from an injectable alginate biomaterial in a model of acute myocardial infarction. Biomaterials. 32:565-578.

108. Ferrara N, Gerber HP, Le Couter J (2003) The biology of VEGF and its receptors. Nat Med 9: 669-676.

109. Betsholtz C, Karlsson L, Lindahl P (2001) Developmental roles of plateletderived growth factors. Bio Essays 23: 494-450.

110. Hao X, Silva EA, Månsson-Broberg A, Grinnemo KH, Siddiqui AJ, et al. (2007) Angiogenic effects of sequential release of VEGF-A165 and PDGF-BB with alginate hydrogels after myocardial infarction. Cardiovasc Res 75: 178-185.

111. Bathgate RA, Samuel CS, Burazin TC, Gundlach AL, Tregear GW (2003) Relaxin: new peptides, receptors and novel actions. Trends Endocrinol Metab 14: 207-213.

112. Hsu SY, Nakabayashi K, Nishi S, Kumagai J, Kudo M, et al. (2002) Activation of orphan receptors by the hormone relaxin. Science 295: 671-674.

113. Dschietzig T, Bartsch C, Stangl V, Baumann G, Stangl K (2004) Identification of the pregnancy hormone relaxin as glucocorticoid receptor agonist. FASEB J 18:1536-1538.

114. Masini E, Bani D, Bello MG, Bigazzi M, Mannaioni PF, et al. (1997) Relaxin counteracts myocardial damage induced by ischemia-reperfusion in isolated guinea pig hearts: evidence for an involvement of nitric oxide. Endocrinology 138: $4713-4720$.

115. Bani D, Masini E, Bello MG, Bigazzi M, Sacchi TB (1998) Relaxin protects against myocardial injury caused by ischemia and reperfusion in rat heart. Am J Pathol 152:1367-1376.

116. Bani D, Nistri S, Sacchi TB, Bigazzi M (2005) Basic progress and future therapeutic perspectives of relaxin in ischemic heart disease. Ann N Y Acad Sci 1041: 423-430.

117. Perna AM, Masini E, Nistri S, Briganti V, Chiappini L, et al. (2005) Novel drug development opportunity for relaxin in acute myocardial infarction: evidences from a swine model. FASEB J 19:1525-1527.
118. Formigli L, Perna AM, Meacci E, Cinci L, Margheri M, et al. (2007) Paracrine effects of transplanted myoblasts and relaxin on post-infarction heart remodeling. J Cell Mol Med 11: 1087-1110.

119. Formigli L, Francini F, Nistri S, Margheri M, Luciani G, et al. (2009) Skeletal myoblasts overexpressing relaxin improve differentiation and communication of primary murine cardiomyocyte cell cultures. J Mol Cell Cardiol 47: 335-345.

120.Nistri S, Pini A, Sassoli C, Squecco R, Francini F, et al. (2012) Relaxin promotes growth and maturation of mouse neonatal cardiomyocytes in vitro: clues for cardiac regeneration. J Cell Mol Med 16: 507-519.

121.Sedmera D, Pexieder T, Vuillemin M, et al. Developmental patterning of the myocardium. Anat Rec 2000; 258: 319-37.

122. Samuel CS (2005) Relaxin: antifibrotic properties and effects in models of disease. Clin Med Res 3: 241-249.

123. Samuel CS, Lekgabe ED, Mookerjee I (2007) The effects of relaxin on extracellular matrix remodeling in health and fibrotic disease. Adv Exp Med Biol 612: 88-103.

124. Pini A, Samuel CS, Shemesh R, Bani D (2012) New views on relaxin and relaxin-receptor agonists for the treatment of lung fibrosis: evidences from in vivo models. AoRM (Ann Respir Med) 3: 65-71.

125. Sassoli C, Chellini F, Pini A, Tani A, Nistr S, et al. (2013) Relaxin prevents cardiac fibroblast- myofibroblast transition via Notch-1-mediated inhibition of TFG $\beta /$ Smad3 signaling. PLoS One 8: e63896.

126. Bonacchi M, Nistri S, Nanni C, Gelsomino S, Pini A, et al. (2009) Functional and histopathological improvement of the post-infarcted rat heart upon myoblast cell grafting and relaxin therapy. J Cell Mol Med 13: 3437-3448.

127. Haider KH, Ashraf M (2012) Preconditioning approach in stem cell therapy for the treatment of infarcted heart. Prog Mol Biol Transl Sci 111: 323-356.

128. Laflamme MA, Chen KY, Naumova AV, Muskheli V, Fugate JA, et al. (2007) Cardiomyocytes derived from human embryonic stem cells in pro-survival factors enhance function of infarcted rat hearts. Nat Biotechnol 25: 1015-1024

129. Formigli L, Ibba-Manneschi L, Perna AM, Pacini A, Polidori L, et al. (2003) Altered Cx43 expression during myocardial adaptation to acute and chronic volume overloading. Histol Histopathol 18: 359-369.

130. Formigli L, Paternostro F, Tani A, Mirabella C, Alessandro, Quattrini Li, Nosi D, Saccardi R, Mazzanti B, Lo Russo G, Zecchi-Orlandini S (2013) Bio-engineered Mesenchymal stromal cell (MSCs) grafts for skin repair/ regeneration. Preclinical aspects. Journal of Regenerative Medicine, [Epub ahead of print]
This article was originally published in a special issue, Cardiac Resident Stem Cells \& Progenitors handled by Editor(s). Dr. Vincenzo Lionetti, Scuola Superiore Sant Anna University, Italy 